\title{
Flávio de Barros, o ilustre cronista anônimo da guerra de Canudos
}

\author{
BERTHOLD ZILLY
}

\author{
As fotografias que Euclides da Cunha \\ gostaria de ter tirado ${ }^{1}$
}

GUERRA DE CANUDOS (1896-1897), evento crucial da história bra-
sileira e um dos atos fundadores da República, tornou-se, graças à
magia da retórica pictorial e teatral de Euclides da Cunha em $O s$

Desde as primeiras edições, esse clássico da historiografia e literatura vem acompanhado de um meio de representação relativamente moderno na produção editorial da época, que reforça o empenho do autor pela presentificação visualizadora: a fotografia. Os canhões diante da serra de Monte Santo, soldados no acampamento em Canudos, as prisioneiras - todos os brasileiros escolarizados conhecem essas imagens. Elas logo passaram - junto com outras tomadas não incluídas em Os sertões, por exemplo, Antonio Conselheiro exumado, um jagunço preso, o leito seco do VazaBarris - a figurar em boa parte da historiografia sobre a Velha República, gravando-se profundamente na memória coletiva, comparáveis com as imagens do padre Anchieta, o grito do Ipiranga, Dom Pedro II com sua imponente barba, o enterro de Getúlio, Vladimir Herzog assassinado, Tancredo agonizante.

Se em Os sertões, diferentemente de outros livros contemporâneos sobre a Guerra de Canudos, constam três dessas fotos, foi porque o repór-

${ }^{1}$ Cícero F. de Almeida, Canudos: imagens da guerra. Os últimos dias da Guerra de Canudos pelo fotógrafo expedicionário Flávio de Barros, Rio de Janeiro, Museu da República/Lacerda, 1997. 
ter-fotógrafo Flávio de Barros realizou um velho anseio do repórter-escritor Euclides da Cunha que, desde cedo fascinado com essa nova tecnologia mimética tida então como reprodução fiel da realidade, levou uma câmara ao sertão, no entanto sem resultados práticos. Não só o olhar do autor científico era aguçado e direcionado por esse modo de ver, mas ele até parece ter escrito algumas cenas lembrando e interpretando fotos de Flávio de Barros. É portanto natural que, para comentá-las mais de um século depois, o organizador dessa edição se valha de trechos de Os sertões. Pois, se mal podemos falar de Canudos sem nos referir a Os sertões, tampouco podemos fazê-lo sem nos lembrar daquelas fotos, cuja notoriedade contrasta curiosamente com o ostracismo do seu criador, nem sequer citado por Euclides, talvez por ser considerado mero copista da realidade, e não artífice.

Ostracismo atenuado hoje em dia, pois agora, graças ao Centenário de Canudos e ao sistema decimal que o condicionou, temos afinal, pela primeira vez em forma de livro, diante de nós, a coleção completa das 69 fotografias da guerra, importante contribuição aos estudos históricos e homenagem póstuma ao fotógrafo semi-anônimo. Devemos esse belo trabalho de pesquisa e editoração ao Museu da República e, mais especificamente, a Cícero de Almeida, chefe da Divisão de Pesquisas, onde se guarda uma das duas únicas coleções completas conservadas até hoje em dia, encontrando-se a outra nas mãos do antropólogo baiano Renato Ferraz. Podese felicitar o Museu e a editora Lacerda pelo empreendimento, há muito esperado e desejado por leigos e especialistas. Tais fotografias, em dois álbuns, um de 15 e outro de 54 tomadas, são as únicas existentes sobre a guerra de Canudos e constituem a parte mais preciosa da escassa iconografia autêntica sobre esse episódio da história brasileira, formada, além disso, por poucos croquis e mapas desenhados por jornalistas e soldados, entre os quais Euclides da Cunha e o tenente-coronel Siqueira de Menezes. Mas elas também prefiguram de alguma maneira os trabalhos de fotógrafos que iriam a Canudos décadas mais tarde: Pierre Verger, Maureen Bisilliat, Walter Firmo, Markus Kirchgessner, Antonio Olavo, Evandro Teixeira, Anna Mariani, entre outros.

Depois de sucinta introdução, esboçando a história da guerra assim como a gênese e repercussão das fotografias, Cícero de Almeida comenta cada uma delas, de modo que quem abre o livro as encontra uma atrás da outra na página da direita, sem texto algum, deixando a imagem falar por si, com o respectivo comentário apresentado na página oposta, à esquerda. Tal organização permite dois tipos de leitura: uma puramente imagética, outra discursiva, enriquecida por valiosas informações históricas. Como a 
seqüência original das fotos - reproduzidas com excelente qualidade, apesar do empalidecimento dos originais - não obedecia a qualquer ordem cronológica ou temática, o seu editor se viu diante da difícil tarefa de organizá-las, resolvendo dividi-las em três grupos, ou seja O território, flagrantes da guerra, A presença do exército - eco longínquo da tríade euclidiana de $A$ terra, $O$ homem, $A$ luta, com inversão da segunda e terceira parte de Os sertões, sendo o homem basicamente o do exército.

Claro que essas tomadas documentam o olhar do vencedor, encenando o triunfo do homem civilizado sobre o inculto, o atrasado, o selvagem, excluindo quase totalmente os aspectos repugnantes da guerra: miséria, fome, crimes, degola. Só uma vez os cadáveres insepultos dos canudenses são tematizados expressamente. As fotos enfatizam, na primeira parte, a aspereza e esterilidade do terreno, a periculosidade da expedição, as dificuldades da vitória; na segunda, a satisfação com a derrota do inimigo e com a destruição da sua cidadela, entremeada com laivos de heroísmo e de luto pelos companheiros mortos em combate; a terceira parte é constituída, de longe, pelo maior número de quadros, cenas anteriores ou posteriores aos combates, longe deles, algumas quase idílicas, apresentando momentos de lazer ou de treino militar, de modo que, aqui, o grau de encenação é maior do que nas outras partes, enfatizando a guerra como aventura, como vivência de camaradagem e companheirismo, de identidade grupal.

Foi a primeira vez que o próprio exército brasileiro fez questão de documentar uma guerra fotograficamente. Essas imagens foram elemento significativo no conjunto dos esforços propagandísticos do exército e das elites, no sentido de uma política de informações e desinformações perante a opinião pública no Brasil e no mundo, com freqüentes comunicados para a imprensa nacional e internacional. Uma das primeiras atividades da quarta e última expedição foi a construção do telégrafo de Queimadas até Monte Santo, posto avançado da civilização perto de Canudos e base das operações, com papel portanto não só estritamente militar. Mediante o controle do telégrafo e, de modo geral, dos correios, o exército praticou uma ferrenha censura, além de ameaças físicas contra correspondentes que divulgassem notícias indesejáveis para a tropa, como no caso do corajoso Manuel Benício, do Jornal do Commercio, obrigado a deixar a zona da guerra.

Outros correspondentes desfrutaram do convívio amistoso com oficiais e comandantes pois, de modo geral, havia estreita colaboração entre a imprensa e o exército, com militares escrevendo artigos e, mais tarde, livros, mas também com jornalistas que eram oficiais da reserva, como Euclides da Cunha, nomeado até como adido do ministro da guerra, ma- 
rechal Bittencourt. Dois dos repórteres mais paparicados foram justamente aqueles cujas matérias tiveram o maior e mais duradouro impacto, e que se tornaram cada vez mais críticos com o decorrer do tempo, sobre a opinião pública: Euclides da Cunha e Flávio de Barros, de origem, formação e destino totalmente diversos, mas ambos contratados de certa forma pelo exército, e ambos testemunhando em última análise, de propósito ou não, contra os seus mandantes.

Mais tarde essas fotos seriam também utilizadas, como escreve Cícero de Almeida, em projeções elétricas para o grande público, anunciadas de modo bem sensacionalista: "Terminada a guerra, tratou o exército de dar ampla divulgação ao material fotográfico de Flávio de Barros, tornando-o objeto de exposição pública. Em 2 de fevereiro de 1898, apenas quatro meses após o final dos combates, a Gazeta de Notícias trazia o seguinte texto de propaganda: “Campanha de Canudos [...] Curiosidade! Assombro!! Horror!!! Miséria!!!!' e convidava seus leitores a assistirem a 'cenas de toda a guerra de Canudos tiradas no campo da ação pelo fotógrafo expedicionário Flávio de Barros, por consenso do comandante em chefe das tropas"”.

Parece-me que o organizador poderia ter mantido os títulos originais das fotos, em vez de substituí-los por títulos mais apropriados e mais elucidativos, politicamente mais corretos do que os do próprio fotógrafo, citados apenas nos respectivos comentários. Por outro lado, os títulos autênticos, que na verdade eram legendas, caracterizações erradas em grande parte, com sua carga ideológica anticonselheirista, faziam, juntamente com os próprios quadros, parte da encenação entre heróica e idílica da história, que valeria a pena ser documentada tal como se apresentava ao contemplador da época. É o caso por exemplo do quadro 400 jagunços presos, reintitulado por Cícero de Almeida como Rendição dos conselheiristas em 2 de outubro, evitando o injurioso termo jagunço e corrigindo o exagero do seu número, já que quase todos os prisioneiros masculinos haviam sido degolados, entre eles Antônio Beatinho, o altareiro de Antônio Conselheiro, de modo que na foto aparecem quase só mulheres.

Devido ao longo tempo de exposição, não poderia haver instantâneos de luta, a não ser em vistas panorâmicas. Algumas fotos se nos afiguram como se fossem tiradas para recordar viagens de clubes esportivos ou de equipes de pesquisadores, o que combina com as denominações que se davam ao empreendimento militar, ou seja, expedições e campanha. Todas as imagens têm algo de estático: os objetos e as pessoas imóveis, não só por motivos técnicos, mas também pelo desejo de pose e ostentação dos pró- 
prios retratados, que queriam levar lembranças, quase suvenires, para familiares e amigos, esposas e noivas.

Ora, essas posturas nos parecem menos marciais do que era de se esperar, pois as óbvias expressões de arrogância, de machismo, de triunfalismo, sobretudo nos combatentes gaúchos posando de bombachas, são atenuadas pelas não menos óbvias privações e carências, ou por pretensas atitudes de generosidade para com os vencidos, ademais por restos do ideal republicano do cidadão armado. Vários oficiais se nos apresentam não fardados, às vezes porém com a vaidade de elegantes freqüentadores da rua do Ouvidor, no meio do sertão, como, em vários quadros, o general Carlos Eugênio de Andrade Guimarães. Quase todos os militares, aliás, estão bem agasalhados, fato surpreendente com temperaturas raramente abaixo de $\mathbf{3 0}$ graus.

Não se pode ignorar certo ar de melancolia naqueles quadros do arraial destroçado, das igrejas em ruínas, do Jagunço preso. Essa última fotografia se transfigura em homenagem talvez involuntária ao inimigo domado, um vaqueiro alto, no seu traje de couro, orgulhoso e nobre, apesar do visível cansaço, escoltado por quatro soldados, mais baixos do que ele, ordinários, medíocres, brutos. Nesse grupo de cinco homens, os quatro vencedores, armados, inexpressivos, dois de cada lado, parecem só ter uma função: enaltecer o inimigo inerme que, porém, nos olha empertigado, impávido, imponente, um vencido vencedor. A tragicidade dessa cena, configurada com quase perfeita simetria, com o preso no centro do grupo, dominando-o, aumenta quando nos lembramos que esse sertanejo que se nos apresenta, antes de tudo, como um forte, como titã subjugado, como encarnação daquilo que Euclides chama de "cerne de uma nacionalidade" - esse herói estava certamente, na hora da tomada, sendo levado para a degola, o que transforma os seus vigias em assassinos e a imagem numa implícita acusação.

Outra fotografia que teve destino diverso do pretendido pelos vencedores, é a do Conselheiro morto, único retrato autêntico do líder sertanejo que, em vez de servir apenas - como queria o exército - como prova da sua morte perante a nação, iria contribuir para que o retratado, no plano simbólico, entrasse na imortalidade. Numa curiosa analogia com outro libertador malogrado das massas camponesas na América Latina, o Che, a fotografia do Conselheiro, embora tirada a mando dos seus assassinos, assemelha-se a representações populares de Cristo, propagando a imagem desse mártir dos sertões como ícone das esperanças de salvação e de renovação, dentro e fora do âmbito rural e religioso. 


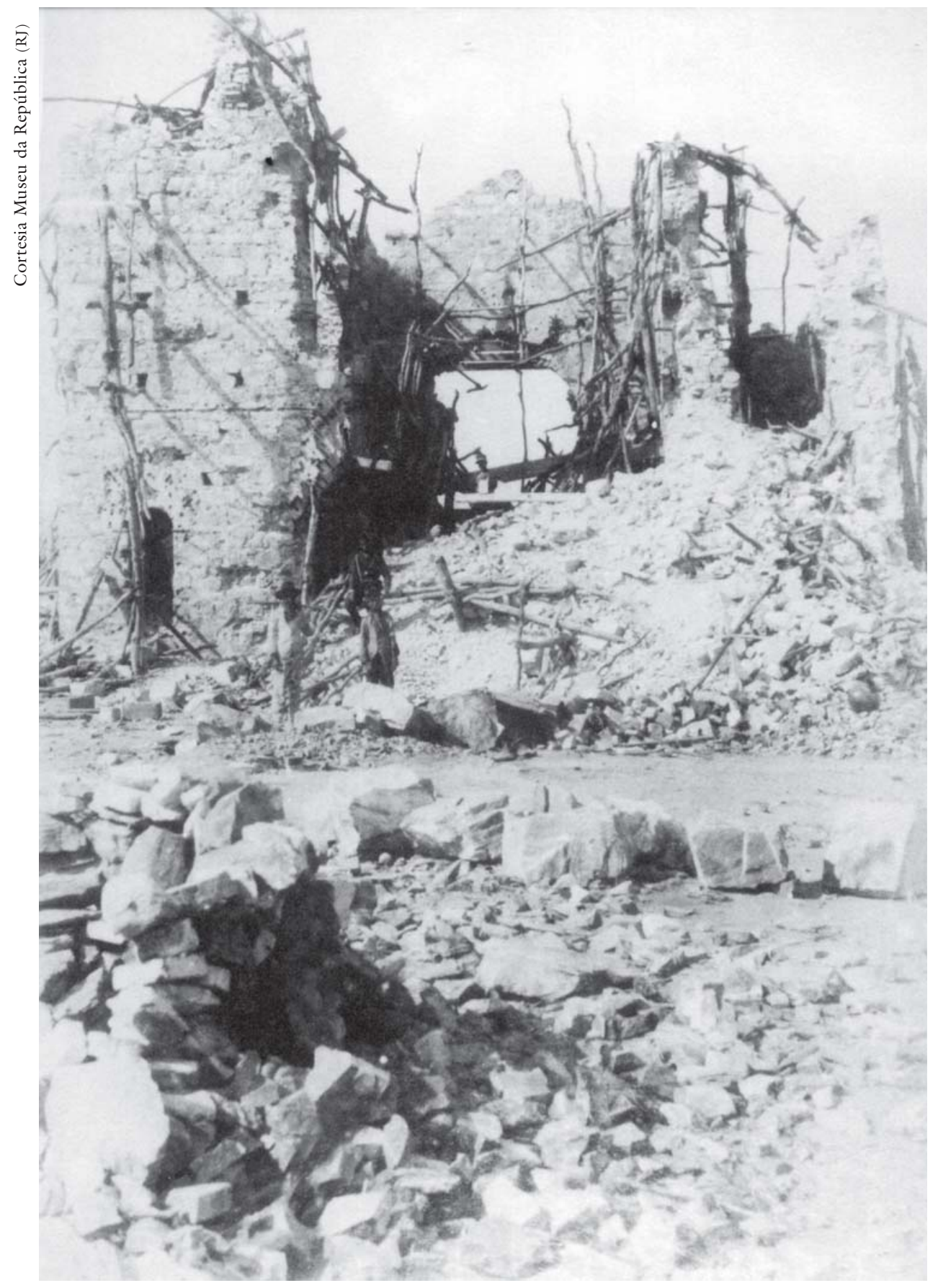

IGREJA DE BOM JESUS - A IGRejA NOva de Canudos, ou de Bom Jesus, foi projetada e construída por orientação de Antônio Conselheiro e serviu como principal reduto da resistência conselheirista no final do conflito. Suas paredes resistentes e suas torres elevadas, onde se postavam exímios atiradores, representaram um forte obstáculo encontrado pelo exército na luta contra o arraial. Em 23 de julho de 1897, o general Artur Oscar, em telegrama enviado ao governo federal, comunicava que faltava apenas dominar o núcleo onde se encontravam as igrejas, após ter avançado sobre grandes extensões da cidadela. Por considerá-la o "poderoso reduto central do inimigo", Artur Oscar comandou um intenso bombardeio contra a igreja do Bom Jesus em 6 de setembro, quando, após seis horas de ataque, caíram as duas torres: "o exército ficara, afinal, livre das seteiras altíssimas de onde o fulminavam os sitiados, porque as duas torres assoberbando toda a linha do assédio, reduziam por toda a banda os ângulos mortos das trincheiras" (Euclides da Cunha). 


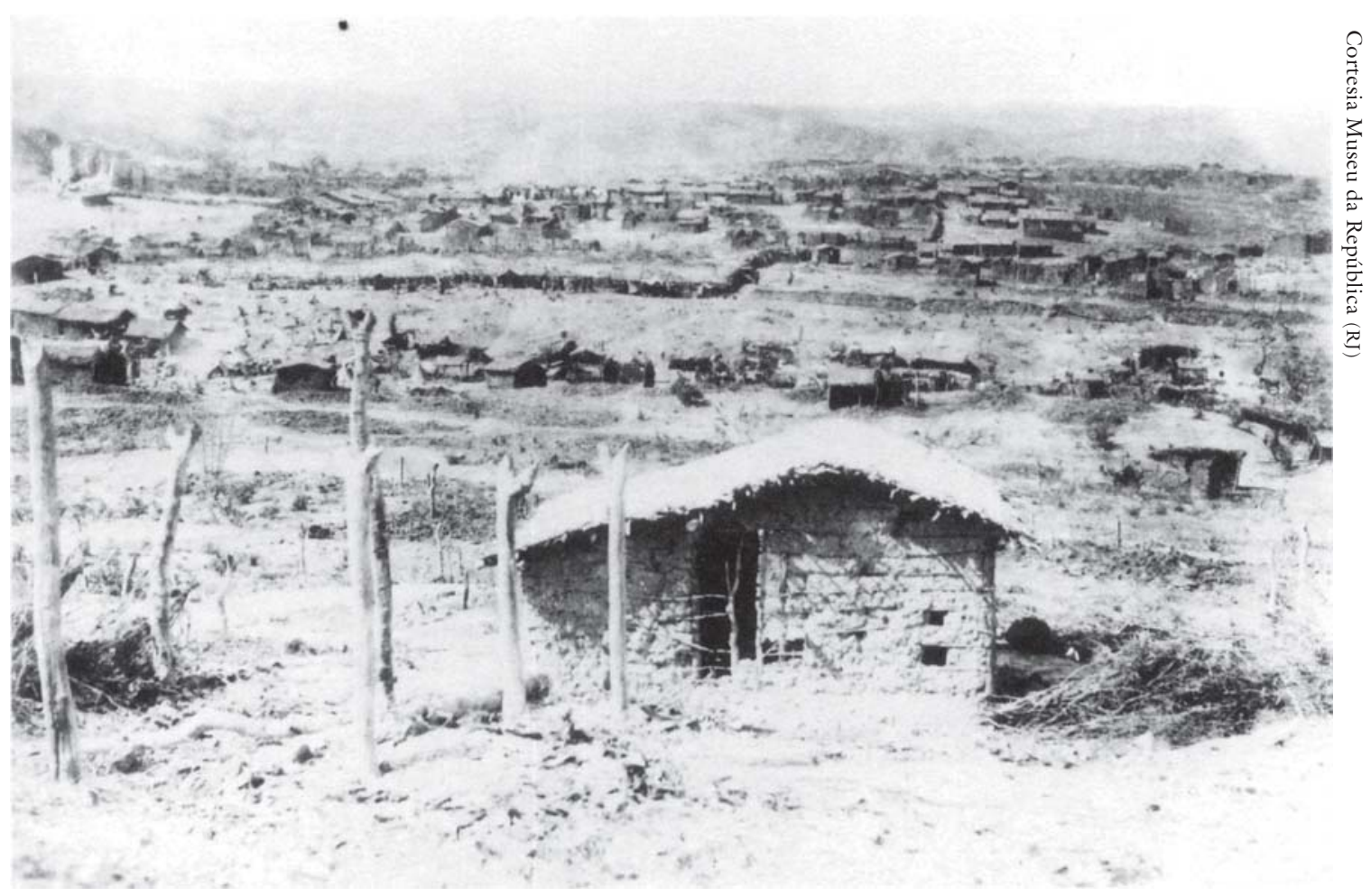

CANUdOS a SUDESTE - EM PRIMEIRo plano, uma típica casa do arraial. Segundo relato do correspondente da Gazeta de Notícias do Rio de Janeiro, Favila Nunes, as construções de Canudos eram de "pau-a-pique, cobertas com folhas de icó com barro por cima ou telha vã. (...) As portas são tão pequenas que é preciso abaixar-se a cabeça para transpô-las; estendendo-se o braço para cima toca-se quase a cumeeira; os caibros e ripas são seguros com cordas ou cipós, as dobradiças das portas e microscópicas janelinhas são de sola, na sua quase totalidade não têm reboco nem caiação, interna ou externa”. À esquerda, ao fundo, as ruínas da Igreja do Bom Jesus.

Mas quem afinal era Flávio de Barros? Mal o sabemos, ainda que agora conheçamos a parte historicamente mais importante do seu trabalho. Parece ter nascido unicamente para acompanhar com sua câmara, durante poucas semanas, aquela guerra fratricida nos confins da civilização, produzindo ilustrações para livros históricos, um mero cronista auxiliar, não interessando a ninguém como indivíduo, diferentemente do seu colega da pena que logo se tornou uma glória nacional. O nome de Flávio de Barros sequer era mencionado na imprensa, não sendo ele considerado correspondente porque na época não era possível publicar fotos em jornais. Só se sabe que esse obscuro fotógrafo baiano foi incumbido pelo exército, sob o comando do general Artur Oscar de Andrade Guimarães, da perigosa e estafante missão de documentar a campanha de Canudos, pouco atraente para os fotógrafos mais renomados da Bahia. Não sabemos se ele foi pago pelo governo, mas é de se supor que não diretamente. De qualquer forma as fotografias, uma mercadoria, eram comercializadas, sendo o exército e os oficiais provavelmente os seus melhores consumidores. 
Não se sabe se foi um bom negócio, talvez nem tanto, porque de outro modo o número de álbuns preservados até hoje deveria ser maior.

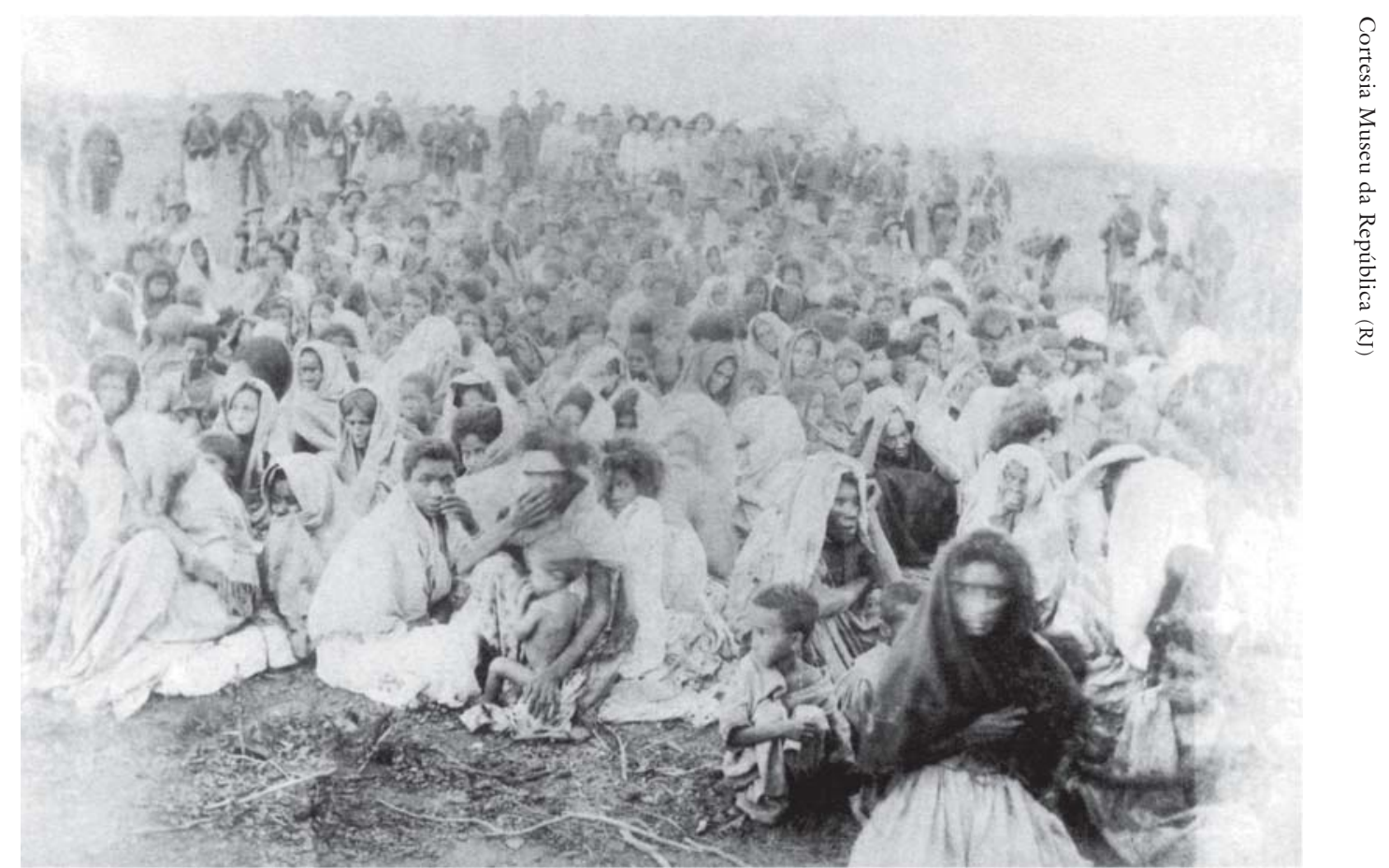

RENDIÇÃO DOS CONSELHEIRISTAS EM 2 DE OUTUBRO - A 2 DE OUTUBRo, um dia após o assalto final ao arraial, soldados do $4^{\circ}$ Batalhão avistaram ainda pela manhã uma bandeira branca; tratava-se de solicitação de trégua vinda de Antônio Beatinho, zelador das imagens de Canudos. Beatinho foi levado à presença do general Artur Oscar - a quem chamava de doutor-general - para negociar a rendição dos sobreviventes, solicitando-lhe garantia de vida. O comandante da Quarta Expedição consentiu na solicitação, impondo, no entanto, o seu caráter incondicional. Beatinho voltou para avisar os sitiados. Até as $17 \mathrm{~h}$ daquele mesmo dia, um elevado contingente já havia se apresentado. Segundo Favila Nunes, da Gazeta de Notícias, foram cerca de 60 homens e mais de 500 mulheres e crianças, que ficaram sob o cerco do Batalhão de Polícia do Pará. O lado dramático da cena foi descrito pelos diversos correspondentes presentes. Favila Nunes, impressionado, assim o relatou: "Mas, que horror!... esqueletos humanos, com as mãos decepadas, ferimentos horríveis e asquerosos, alguns apodrecidos". A fotografia desses prisioneiros é, certamente, uma das mais conhecidas imagens do conjunto, intitulada por Flávio de Barros 400 jagunços prisioneiros. Revela o dramático estado dos sitiados, muitos sem água e comida havia vários dias. A maioria dos prisionerios na fotografia é constituída por mulheres, algumas amamentando seus filhos, crianças e homesn em menor quantidade (ao fundo).

Enquanto Euclides, mesmo antes de iniciar a redação do seu livro já era tido, entre os outros jornalistas no teatro da guerra, como escritor, não há notícias sobre eventuais pretensões artísticas ou historiográficas de Flávio de Barros. O fotógrafo conseguiu, porém, entre a massa de típicas lembranças de soldados, posando ele mesmo de modo quase cômico, criar 
algumas imagens extremamente bem compostas, depoimentos emocionantes e inesquecíveis. Por um instante saiu da total obscuridade, iluminado pela luz de ribalta daquele palco da História nos sertões, sumindo de novo no anonimato, de modo que hoje nem conhecemos o ano de sua morte.

É curioso que esse pioneiro da fotografia militar no Brasil ainda não se tenha tornado assunto de estudo biográfico ou protagonista de obra ficcional. Ele pertence a uma categoria de testemunhas com que intelectuais, sejam autores ou leitores, podem facilmente se identificar, como acontece com personagens no romance de Vargas Llosa La Guerra del fin del mundo, no filme de Sérgio Rezende A Guerra de Canudos ou em o Baile perfumado, filme de Paulo Caldas e Lírio Ferreira. O repórter, o cineasta, o escritor, o cientista social, enquanto cronistas, desempenham tarefa atraente, pois criam a imagem que a opinião pública e a posteridade terão de fatos históricos. Eles são os primeiros intérpretes do passado, os formadores da memória, de certa forma, os criadores da História. Têm uma missão ao mesmo tempo nobre e perigosa, de alta responsabilidade e de muitas tentações, que os coloca entre os partidos, entre vencedores e vencidos: documentar, selecionar, interpretar, justificar ou criticar o ocorrido, situações importantes e eventos decisivos, mediante palavras ou imagens, a serviço da Verdade, o que é particularmente difícil em tempos de guerra.

Berthold Zilly é doutor em Romanística e professor do Instituto Latino-Americano (Lateinamerika-Institut) da Universidade Livre de Berlim (Alemanha). Traduziu Os sertões, de Euclides da Cunha, para o alemão. 